\title{
Results after Two Years of Non-operative Treatment of Occlusal Surface in Children with High Caries Prevalence
}

\author{
Marisa MALTZ \\ Berenice BARBACHAN e SILVA \\ Danusa Queiroz de CARVALHO \\ Alexandre VOLKWEIS \\ Department of Social and Preventive Dentistry, Faculty of Dentistry, Federal University of Rio Grande do Sul, \\ Porto Alegre, RS, Brazil
}

\begin{abstract}
The aim of this study was to describe the 2-year results of an individualized treatment program designed to control occlusal caries in erupting first permanent molars. The sample consisted of 145 five-to-six-year-old students divided into a control group ( $\mathrm{n}=71)$ and a test group $(\mathrm{n}=74)$. All test children received a biannual basic preventive program and a recall system according to individual disease activity. The basic program consisted of 3 (March) and 2 (August) sessions of oral hygiene orientation and toothbrushing with fluoride gel. The analysis of the baseline and 1-2-year data showed a significant reduction in the number of active lesions in the test group. In the control group, there were initially 70 active lesions and after two years 68 surfaces remained with disease and 24 surfaces had been filled. The children in the test group had 80 surfaces with active lesions initially and after two years only 3 surfaces with disease remained. From the 15 cavitated lesions, only 5 surfaces needed to be filled. This program showed that care of erupting teeth on an individualized basis can control occlusal caries.
\end{abstract}

Key Words: dental caries, occlusal surface, disease activity, tooth eruption.

\section{INTRODUCTION}

The occlusal surface is the most susceptible surface for caries due to its anatomic configuration. In countries where dental caries are becoming less prevalent (1) remaining lesions generally occur on occlusal surfaces $(2,3)$. In order to maximize reduction in dental caries, additional studies on diagnosis and treatment of this surface are needed (4). The use of invasive procedures to diagnose and treat the occlusal surface has been a widespread procedure. Treatment of the occlusal surface was either the elimination or obliteration of surface irregularities - odontomy or preventive restorations (5). These methods often caused an elimination of sound tissue. Later, sealants became an alternative method to control the development of caries in this surface. The use of sealants as a single preventive measure has not been considered an effective treatment (6).
Thus, it is important to study the possibility of diagnosis and control of the caries process on occlusal surfaces without the use of obliteration (sealants) and invasive procedures. Because it is known that the eruption period is the most critical for development of occlusal caries (7), the aim of this investigation was to analyze the effect of an individualized treatment program designed to control occlusal caries in erupting first permanent molars based on patient education and fluoride application.

\section{MATERIAL AND METHODS}

Two hundred and one 5-6-year-old children from two Public Schools of Porto Alegre (Brazil) began this study. The children were divided into two groups; one school acted as control and the other as test. Both schools were located in a central area of the city. The 
control and test group children had similar caries experience in the deciduous and permanent dentition at the beginning of the study ( $>>0.05)$. These schoolchildren did not participate in any dental health program. During the study period (1992-1994), 56 children changed schools, giving a final sample of 145 subjects (control group, $\mathrm{n}=71$ and test group, $\mathrm{n}=74$ ).

\section{Clinical Examination}

The children were examined at the beginning of the study and after 1 and 2 years in terms of stage of eruption of first permanent molar, gingival inflammation and dental caries status. The stage of eruption of each molar was recorded as previously described by Carvalho et al. (8). The following criteria were used: 0 $=$ unerupted; $1=$ occlusal surface partially erupted; $2=$ occlusal surface fully erupted, but more than half of the facial surface was covered with gingival tissue; $3=$ occlusal surface was erupted, and less than half of the facial surface covered with gingival tissue; $4=$ full occlusion. Gingival inflammation was determined by measuring the Bleeding Index. The examination of dental caries was determined by the DMFS Index, according to Gustafson et al. (9), after plaque removal and air-drying the surface. The presence of non-cavitated lesions, cavitated lesions, fillings (F) and sealants (Se) was recorded. The lesions were classified according to the following criteria: 1) active non-cavitated lesion $(\mathrm{ANC})=$ opaque enamel with a dull-whitish surface; 2 ) inactive non-cavitated lesion (INC) = shiny appearance of the surface area with a white or different degrees of brownish discoloration; 3 ) active cavitated lesion $(\mathrm{AC})=$ localized surface destruction with active characteristics (dull-whitish enamel and soft dentin with light brown color); 4) inactive cavitated lesion (IC) $=$ localized surface destruction with arrested characteristics (shiny, hard surfaces with different degrees of brownish discoloration).

Two dentists examined the children (B.B.S and D.Q.C.). Duplicate records were made on eighty children with a total of 320 molars (Kappa coefficient = $0.83)$.

\section{Design of the Experiment and Treatment Procedures}

The control group children received no free dental treatment at the school. The test group children received a biannual basic program and recall sessions based on their individual caries activity. The children, their parents and teachers were informed about oral health and how to promote it. The biannual basic program consisted of two blocks of 3 weeks (1st semester) and 2 weeks ( 2 nd semester). In these weekly control blocks, the children received oral health education, supervised oral hygiene and toothbrushing with $1.23 \%$ fluoride gel for $1 \mathrm{~min}$. One month after the basic program, the children were reevaluated according to caries activity and gingival inflammation. The children were then classified into 3 groups: 1) healthy; 2) with gingival bleeding without active caries lesions; 3 ) with active caries lesions with or without gingival bleeding. Each group was submitted to different treatments: group 1: received no other treatment than the basic program; group 2: received oral health education and weekly supervised oral hygiene until gingival bleeding was controlled; group 3: the children with caries activity received monthly recalls, with oral health education, supervised oral hygiene and toothbrushing with $1.23 \%$ fluoride gel until the arrestment of the lesions. The cariogenic activity of all groups was reevaluated every year and the children treated according to their situation. The children with gingival bleeding received individualized treatment only during the first year; in the second year, they received only the biannual basic program. The parents of caries-active children were called before the vacation period and asked to take special care of oral hygiene and the frequency of sucrose consumption of their children.

The parents of the test children gave informed consent for their children to participate in the program. The parents of the control children gave consent for their children to be examined clinically. The diagnosis was given to the parents to seek dental treatment.

Differences between control and test groups were analyzed using the Student's t-test.

\section{RESULTS}

The test and control group children had high caries experience in the deciduous dentition at the beginning of the study. From the 145 children, only $21 \%(n=31)$ had no caries in the deciduous dentition at 5-6 years of age and $16 \%(n=23)$ had more than 11 carious lesions.

At the beginning of the study, there were no 
statistically significant differences for the DMFS Index between the control $(1.41 \pm 1.44)$ and test groups (1.32 $\pm 1.47)$. After 1 and 2 years, an increased caries experience in the control group was observed ( $1^{\text {st }}$ year: $1.75 \pm$ 1.61 and $2^{\text {nd }}$ year: $\left.2.04 \pm 2.02, \mathrm{p}<0.05\right)$ while at one year, there was already a decrease in the test group $\left(1^{\text {st }}\right.$ year: $0.90 \pm 1.39$ and $2^{\text {nd }}$ year: $0.93 \pm 1.46, p<0.05$ ).

At the beginning of the study, there were no first permanent molars in full occlusion in the control group and only 5\% in the test group. Twenty-seven percent and $34 \%$ of the children did not have first permanent molars erupted in the control and test groups, respectively. At the end of the second year, almost all children had erupted first permanent molars.

The clinical situation of the occlusal surface at baseline, and after 1 and 2 years in relation to the stages of eruption are reported in Figure 1. In the control group, after 1 year, the percentage of active lesions

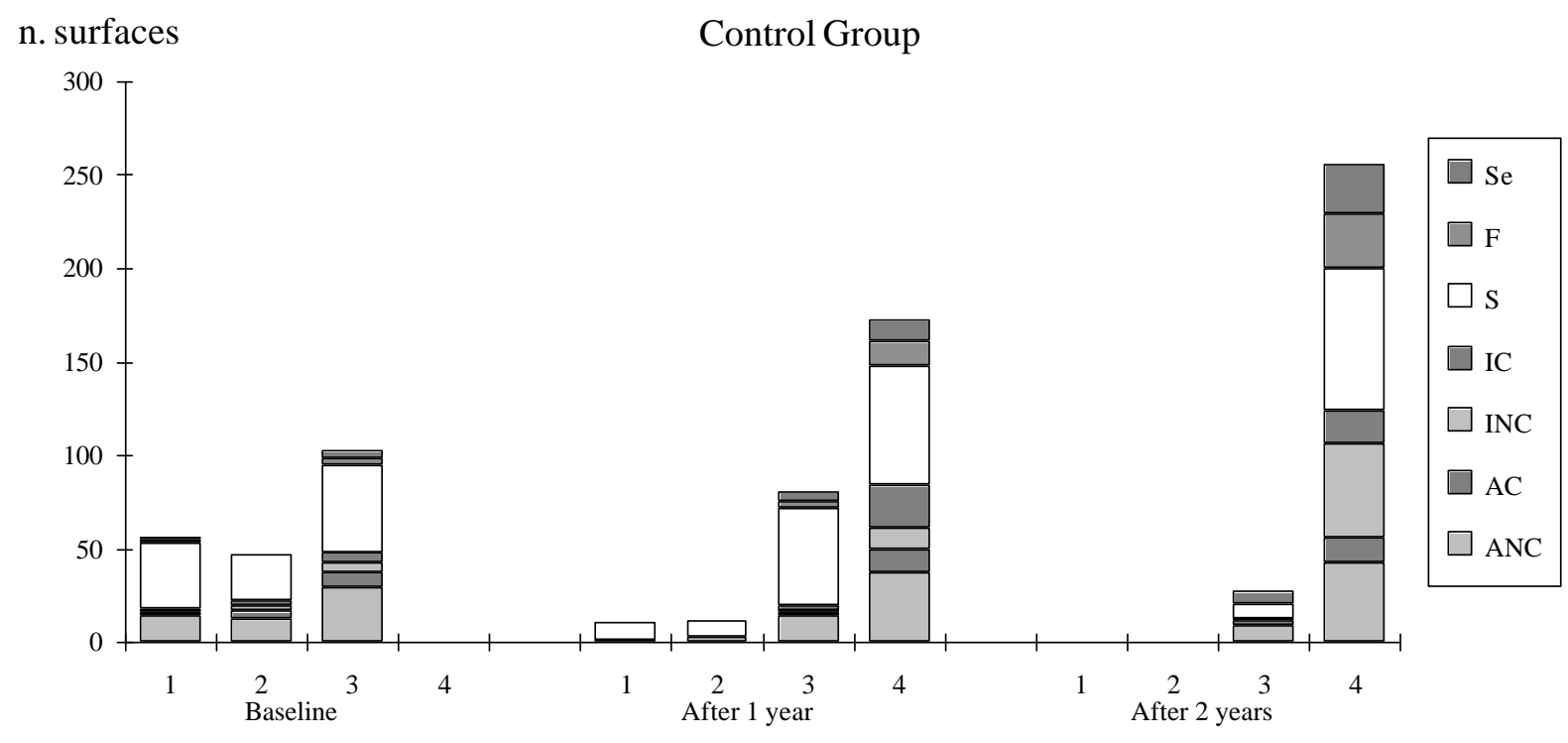

n. surfaces

Test Group

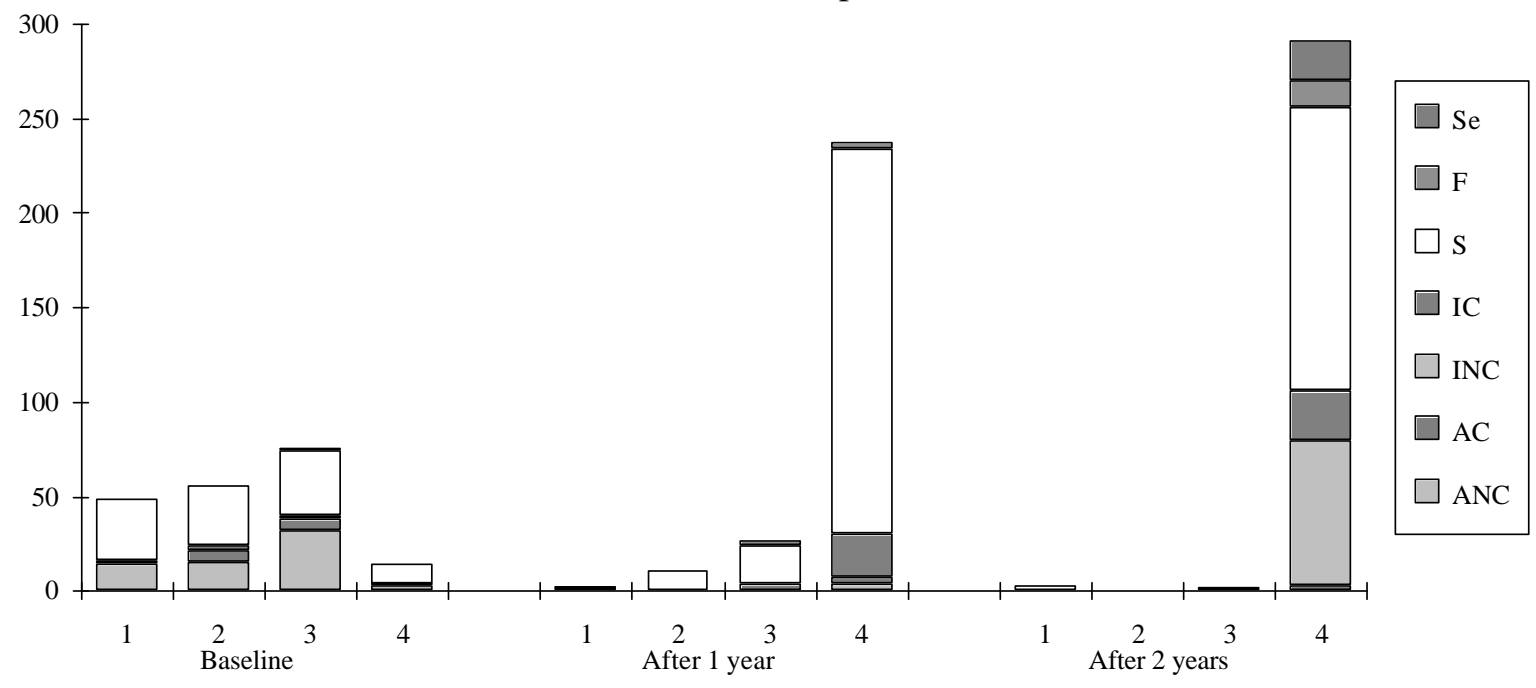

Figure 1. Clinical situation of the occlusal surface of the first permanent molar in each stage of eruption $(1,2,3,4)$ in relation to degree of eruption of the control and test groups. ANC = active non-cavitated lesion; $\mathrm{AC}=$ active cavitated lesion; $\mathrm{INC}=$ inactive non-cavitated lesion; $\mathrm{IC}=$ inactive cavitated lesion; $\mathrm{S}=$ sound; $\mathrm{F}$ = filled surface; $\mathrm{Se}=$ sealed surface. 
(ANC and AC) of teeth partially erupted was similar to teeth in full occlusion. However, after 2 years, because the teeth had been in full occlusion for a longer period of time, the percentage of active lesions was higher $(\mathrm{p}<0.05 \%)$ in the partially erupted teeth than in full occlusion teeth. In addition, inactive lesions were mainly observed in fully erupted teeth. The relation inactive/ active lesion was higher in fully erupted teeth than in partially erupted teeth. The same tendency was observed in the test group; however this group showed almost no active lesions in full occlusion teeth already after 1 year.

The state of each surface during the 2-year period of the control and test children is reported in Table 1. In the control group, there were initially 70 active occlusal surfaces lesion (56 ANC and $14 \mathrm{AC}$ ) and after two years remained 68 occlusal surfaces with the disease (52 ANC and 16 AC). The number of "clinically stable surfaces" (sound, inactive non-cavitated lesion or sealed) was $168(59 \%)$. Twenty-eight $(11 \%)$ surfaces progressed to cavitation stage (unerupted $+\mathrm{S}+\mathrm{INC}+\mathrm{Se}+\mathrm{ANC}$

Table 1. State of each occlusal first permanent molar surface at baseline and after two years.

\begin{tabular}{lrrrrrr}
\hline & Baseline & \multicolumn{5}{c}{ 2 years } \\
\cline { 3 - 7 } & & S+INC+Se & ANC & AC & IC & F \\
\cline { 3 - 7 } Control Group & & & & & & \\
Unerupted & 77 & 46 & 26 & 3 & 0 & 2 \\
S+INC+Se & 123 & 89 & 13 & 7 & 10 & 4 \\
ANC & 56 & 31 & 11 & 3 & 5 & 6 \\
AC & 14 & 0 & 2 & 3 & 2 & 7 \\
IC & 9 & 2 & 0 & 0 & 2 & 5 \\
F & 5 & 0 & 0 & 0 & 0 & 5 \\
Total & 284 & 168 & 52 & 16 & 19 & 29 \\
& & & & & & \\
Test Group & & & & & & \\
Unerupted & 101 & 95 & 0 & 1 & 2 & 3 \\
S+INC+Se & 110 & 101 & 0 & 1 & 5 & 3 \\
ANC & 64 & 54 & 0 & 1 & 8 & 1 \\
AC & 15 & 0 & 0 & 0 & 10 & 5 \\
IC & 5 & 0 & 0 & 0 & 2 & 1 \\
F & 1 & 0 & 0 & 0 & 0 & 1 \\
Total & 296 & 250 & 0 & 3 & 27 & 14 \\
& & & & & &
\end{tabular}

The first column indicates the clinical diagnosis at baseline and the other columns the changes that took place during the study period. $\mathrm{S}=$ sound, $\mathrm{INC}=$ inactive non-cavitated lesion, $\mathrm{Se}=$ sealed surface, $\mathrm{ANC}=$ active non-cavitated lesion, $\mathrm{AC}=$ active cavitated lesion, $\mathrm{IC}=$ inactive cavitated lesion, $\mathrm{F}=$ filled surface. progressed to $\mathrm{AC}+\mathrm{IC})$. Of these new cavitated lesions, 13 were active lesions and 15 were inactive small lesions. Twelve non-cavitated surfaces at the beginning of the study were filled surfaces after 2 years. The number of active lesions in the test group was similar to the control group at the beginning of the study (64 ANC and $15 \mathrm{AC}$ ). Ten of these active cavitated lesions showed characteristics of arrestment after 2 years and 5 occlusal surfaces needed restorative treatment because they were lesions where it was impossible to control the plaque accumulation. Eighty-four percent $(n=250)$ of the sites in occlusal enamel surfaces of first permanent molars of the test children remained "clinically stable" over the 2year period. Eighteen surfaces $(6 \%)$ progressed to cavitation stage (unerupted+S+INC+Se+ANC progressd to $\mathrm{AC}+\mathrm{IC})$. It is important to point out that only 3 of these cavitated lesions were active ones and 15 were small cavities with characteristics of inactive lesions. Seven non-cavitated surfaces at the beginning of the study were filled during the course of the study by private dentists without the indication of the study group. These surfaces were either sound or with arrested lesions.

The distribution of children in terms of the number of occlusal active lesions is reported in Table 2. At baseline, there was a similar distribution of occlusal active lesions in the control and test groups (38\% and $42 \%$ of children had no active lesions, respectively). At the end of the first and second years, the control group maintained a similar distribution, while in the test group a tendency for a concentration of children with fewer active lesions (96\% of children had no active lesions at the second year) was observed.

The number of recall visits necessary to control occlusal caries activity, in the study group, is reported in the Table 3. In the first year, $53 \%$ of children needed no recall visits in addition to the basic program. This percentage in the second year was $82 \%$. The number of recall visits was reduced during the studied period. In the first year, 19 children needed 3-7 recall visits, and after 2 years only 3 children need 3-5 recall visits.

The effect of motivation on oral hygiene was evaluated through the decrease of gingival bleeding. After two years of study, there was a reduction of $52 \%$ in the gingival bleeding in the study group (baseline: $31.16 \pm 18.78$; after two years: $15.02 \pm 12.60$; $\mathrm{p}<0.05$ ) In the control group, there was no significant difference between the two periods (baseline: $23.53 \pm 15.02$; after two years: $22.80 \pm 15.09$ ). 


\section{DISCUSSION}

The present study demonstrates that a two-year preventive program, based on individualized disease activity, can prevent and control caries on the occlusal surface, including lesions of enamel and dentin.

Although the children received fluoride in water and almost all Brazilian toothpastes are fluoridated, their caries experience was high compared to other studies $(1,3)$. Comprehensive public oral health care (preventive or conservative treatment) is not provided to this population free of charge. Only $21 \%$ of the children were caries free at 5-6 years which differs greatly from the WHO goal for the year 2000 that is $50 \%$ caries-free children at this age. Although the caries experience has decreased in Porto Alegre in the last 20 years (10), children still have a high prevalence of caries as shown by the DMFS values of the 7-8-year-old control group children $(2.04 \pm 2.02)$. The disease is mostly concentrated on the occlusal surfaces, but other

Table 2. Distribution of children according to the number of active lesions (non-cavitated and cavitated) on the occlusal surface of the first permanent molar.

\begin{tabular}{lrrrrrrr}
\hline & \multicolumn{3}{c}{ Test } & & \multicolumn{3}{c}{ Control } \\
\cline { 2 - 5 } \cline { 6 - 8 } Lesions & Baseline & 1 year & 2 years & & Baseline & 1 year & 2 years \\
\hline 0 & 31 & 67 & 71 & & 27 & 38 & 35 \\
1 & 15 & 5 & 3 & & 18 & 12 & 17 \\
2 & 17 & 2 & 0 & & 13 & 9 & 11 \\
3 & 7 & 0 & 0 & & 12 & 8 & 3 \\
4 & 4 & 0 & 0 & & 1 & 4 & 5 \\
\hline
\end{tabular}

Table 3. Number of recall visits during the experimental period.

\begin{tabular}{crc}
\hline & \multicolumn{2}{c}{ Number of children } \\
\cline { 2 - 3 } Recall visits & First year & Second year \\
\hline 0 & 39 & 61 \\
2 & 16 & 10 \\
3 & 10 & 1 \\
4 & 4 & 1 \\
5 & 2 & 1 \\
6 & 2 & 0 \\
7 & 1 & 0 \\
Total & 74 & 74 \\
\hline
\end{tabular}

surfaces are also affected. The disease experience of these children shows the necessity of additional preventive measures to control caries.

In Brazil, children begin public school education at 5-6 years of age, a time when the first permanent molars are under eruption, the most critical period for caries initiation on occlusal surfaces. Occlusal surface of erupting teeth is more caries prone due to favorable conditions for plaque accumulation. It is believed that mechanical physiological forces of full occlusion disturb the plaque accumulation making these surfaces less susceptible to caries development $(7,8)$. Backer Dirks (11) has already reported that many of the caries lesions on buccal surfaces that developed soon after eruption were sound $(51 \%)$ or unchanged $(36 \%)$ after 7 years. He considered the lesions' arrest to be mainly a result of physiologic passive exposure of the tooth leading to a change in local conditions for plaque accumulation. Studying first permanent molars, Carvalho et al. (8) observed a significant reduction in easily detectable plaque formed after $48 \mathrm{~h}$ without oral hygiene in fully erupted teeth compared to partially erupted teeth. They also found that the proportion of active lesions was reduced in fully erupted teeth and arrested lesions were mainly observed in the same group.

The reason for treating 5-6-year-old children in this study was to make it possible to control the disease during eruption of their first permanent molars. At the beginning of the study, some children already had erupted first permanent molars with caries (non-cavitated and cavitated dentin lesions). Children participating in the test group had non-cavitated and some of the cavitated lesions were controlled (arrested). This was probably not only the result of the treatment program but also the increased number of first permanent molars in full occlusion as indicated by the data of the control group children. The control children who did not participate in any preventive program had a large number of active non-cavitated and cavitated lesions throughout the study. However, it is important to point out that of the 56 surfaces with non-cavitated lesions at the age of 5-6 years, $31(55 \%)$ were sound at the age of 7-8 and $16(29 \%)$ did not progress or progressed to small arrested cavitated dentin lesions. Moreover, it is clear from the control group data that there was a higher number of active lesions in partially erupted teeth than in the fully erupted ones. In contrast, arrested lesions 
were mainly seen in fully erupted teeth. This suggests that maintenance of tooth integrity in the oral cavity is also related to mechanical wear during natural function and mastication preventing bacterial growth on teeth (11).

A program based on individualized disease activity can promote oral health, restricting over-treatment and lowering program cost, because it treats only specific necessities of each person. It is known that only $25 \%$ of the individuals are responsible for the highest caries prevalence (12) being more rational to invest resources directed to disease-active children reducing the recalls for healthy people who do not need treatment. In this study, the individualized recall system showed a decrease in the number of recall visits from the first to the second year. In the second year, only a small number of children needed recall visits to control caries disease (Table 3 ). The children received individualized recall visits according to their gingival inflammation only in the first period. The subsequent recall visits were planned only regarding their caries activity. This standardized treatment in relation to gingival bleeding reduced gingival inflammation. This indicates that individualized treatment applied to caries should also be extended to periodontal disease.

Periodic toothcleaning associated with topical fluoride application resulted in caries activity control. Some authors have already reported that periodic toothcleaning (13) or simply periodic plaque disturbance (14) can control disease. Programs based on patient education, intensive home-based plaque control and professional toothcleaning can control dental caries $(7,15,16)$. However, these studies used fluoride applications in patients when plaque control was not sufficient to prevent disease. In these studies, as in the present one, it is difficult to measure the role tooth cleaning or fluoride applications had on the control of caries disease. Studies that used only oral hygiene had controversial results (17).

Considering the role that bacteria and their metabolic products play in the caries process, the time for "bacterial invasion" was considered borderline from non-operative to operative treatment. As bacteria invasion in enamel lesions is limited, arrestment of noncavitated lesions has been widely accepted (18). Arrestment of dentin caries has been discussed because it is well established that proper invasion of bacteria is noted after exposure of dentin to the bacteria biomass.
However, authors have demonstrated the possibility to arrest active root dentin lesions (19). Since dentin root lesions can be arrested by non-operative treatment, it is possible to conclude that superficial bacteria invasion to dentinal tubules per se cannot be used as an indication for operative treatment (4). Lesions can be converted from active to inactive stages by surface plaque removal (20), demonstrating that no antimicrobial or operative treatment is required to eliminate microorganisms present within the dentinal tubules.

The treatment of dentin coronal cavities, especially in occlusal surfaces, has almost always been associated with invasive techniques. In this study, occlusal cavitated lesions showed clinical signs of arrestment after non-operative treatment (control of etiologic factors and fluoride application).

The present study indicates that it is possible to control caries disease with non-operative treatment based on individualized disease activity. Moreover, the possibility to control caries lesions including noncavitated and cavitated ones was demonstrated. It is, therefore, possible to enforce a non-invasive practice even in occlusal surface in place of traditional therapy based on invasive procedures to control the disease.

\section{RESUMO}

O objetivo deste estudo foi descrever os resultados de dois anos de um programa de tratamento individualizado desenhado para controlar cáries oclusais em primeiros molares permanentes em erupção. A amostra consistiu de 145 estudantes de 5-6 anos divididos em um grupo controle $(n=71)$ e um grupo teste $(n=74)$. Todas as crianças do grupo teste receberam um programa preventivo básico bianual e um sistema de reconsultas de acordo com a sua atividade de doença individual. O programa básico consistiu de 3 (março) e 2 (agosto) sessões de orientação de higiene oral e escovação com gel fluoretado. A análise dos dados iniciais e de um e dois anos, apresentou uma significativa redução no número de lesões ativas no grupo teste. No grupo controle existiam inicialmente 70 lesões ativas, depois de 2 anos permaneciam 68 superfícies com doença e 24 superfícies haviam sido restauradas. As crianças do grupo teste tinham, no início do estudo, 80 superfícies com lesões ativas e depois de 2 anos permaneciam ativas apenas 3 superfícies. Das 15 lesões cavitadas, apenas 5 precisaram ser restauradas. O programa mostra que cuidados especiais individualizados a crianças com os dentes em erupção podem controlar as cáries oclusais.

\section{REFERENCES}

1. König KG. Role of fluoride toothpastes in caries - preventive strategy. Caries Res 1993;27(suppl 1):23-28. 
2. Lussi A. Validity of diagnostic and treatment decisions of fissure caries. Caries Res 1991;25:296-303.

3. Ekstrand KR, Ricketts DN, Kidd EA. Occlusal caries: pathology, diagnosis and logical management. Dent Update 2001;28:380387.

4. Ricketts DNJ, Ekstrand KR, Kidd EAM, Larsen T. Relation of visual and radiographic ranked scoring systems for occlusal caries detection to histological and microbiological evidence. Oper Dent 2002;27:231-237.

5. Meurmann JH. Fissure sealing in occlusal caries prevention Clinical and experimental studies. Proc Finn Dent Soc 1977;73:745

6. Mitchell L, Murray J. Fissure sealants: a critique of their cost effectiveness. Community Dental Oral Epidemiol 1989;17:19 23

7. Carvalho JC, Ekstrand KR. Thylstrup A. Results of 3 years of non operative occlusal caries treatment of erupting permanent first molars. Community Dent Oral Epidemiol 1992;20:187-192.

8. Carvalho JC, Ekstrand KR, Thylstrup A. Dental plaque and caries on occlusal surfaces of first permanent molars in relation to stage of eruption. J Dent Res 1989;68:773-779.

9. Gustafson BE, Quensel CE, Lanke LKS, et al. The Vipeholm dental caries study. The effect of different levels of carbohydrate intake on caries activity in 436 individuals observed for five years (Sweden). Acta Odontol Scand 1954;11:232-264

10. Maltz M, Shoenardie AB, Carvalho JC. Dental caries and gingivitis in schoolchildren from the municipality of Porto Alegre, Brazil in 1975 and 1996. Clin Oral Invest 2001;5:199-204.

11. Backer Dirks O. Posteruptive changes in dental enamel. J Dent Res 1966;45(suppl 3):503-511.
12. Bruun C, Bille J, Hansen KT, Kann J, Qvist V, Thylstrup A. Three-year caries increments of fluoride rinses or topical applications with fluoride varnish. Community Dent Oral Epidemiol 1985;13:299-303.

13. Axelsson P, Lindhe J, Nyströn B. On the prevention of caries and periodontal disease. Results of a 15-year-longitudinal study in adults. J Clin Periodontol 1991;18:182-189.

14. Holmen L, Mejare J, Malmgren B, Thylstrup A. The effect of regular professional plaque removal on dental caries in vivo. A polarized light and scanning electron microscopy study. Caries Res 1988;22:250-256.

15. Arrow P. Oral hygiene in the control of occlusal caries. Community Dent Oral Epidemiol 1998;26:324-330.

16. Ekstrand KR, Kuzmina IN, Kuzmina E, Christiansen MEC. Two and a half-year outcome of caries-preventive programs offered to groups of children in the Solntvesky District of Moscow. Caries Res 2000;34:8-19.

17. Bellini HT, Arnenberg P, Von Der Fehr FR. Oral hygiene and caries. A review. Acta Odontol Scand 1981;39:257-265.

18. Holmen L, Thylstrup A, Artun J. Clinical and histological features observed during the arrestment of active enamel carious lesions in vivo. Caries Res 1987;21:546-554.

19. Nyvad B, Fejerskov O. Active root surface caries converted into inactive caries as a response to oral hygiene. Scand J Dent Res 1986; $94: 281-288$.

20. Nyvad B, Fejerskov O: Active and inactive root surface caries structural entities? In: Thylstrup A, Leach AS, Qvist V. Eds. Dentine and dentine reactions in the oral cavity. Oxford: IRL Press; 1987. p 165-179.

Accepted October 7, 2002 